Negative pressure wound treatment for uterine incision necrosis following a cesarean section

Dedes, Ioannis ; Krähenmann, Franziska ; Ghisu, Gian-Piero ; Birindelli, Esther ; Zimmermann, Roland ; Ochsenbein, Nicole

DOI: https://doi.org/10.1515/crpm-2015-0100

Posted at the Zurich Open Repository and Archive, University of Zurich ZORA URL: https://doi.org/10.5167/uzh-130036

Journal Article

Published Version

Originally published at:

Dedes, Ioannis; Krähenmann, Franziska; Ghisu, Gian-Piero; Birindelli, Esther; Zimmermann, Roland; Ochsenbein, Nicole (2016). Negative pressure wound treatment for uterine incision necrosis following a cesarean section. Case Reports in Perinatal Medicine, 5(2):105-108.

DOI: https://doi.org/10.1515/crpm-2015-0100 


\section{Negative pressure wound treatment for uterine incision necrosis following a cesarean section}

DOI 10.1515/crpm-2015-0100

Received December 7, 2015. Accepted May 4, 2016. Previously published online June 8, 2016.

Abstract: Extended-spectrum $\beta$-lactamase sepsis with concurrent uterine incision dehiscence after cesarean section with T-shaped incision for chorioamnionitis occurred in a 29-year-old patient after her first delivery. Following an exploratory laparotomy with a diagnosis of necrosis of the anterior uterine wall, a uterine negative-pressure wound treatment (NPWT) was performed, successfully avoiding hysterectomy and enabling secondary suture of the uterine wall.

Keywords: Infectious post-cesarean uterine wall dehiscence; negative-pressure wound therapy; uterine incisional dehiscence; uterine incisional necrosis.

\section{Introduction}

It is estimated that infectious uterine incisional dehiscence, a rare and severe complication, occurs in 1:7001:2400 cesarean section cases [1]. This condition is potentially lethal, due to either sepsis or uncontrolled secondary bleeding, and hysterectomy is considered the standard treatment [2].

Herein, we report a case of septic uterine incisional dehiscence due to abscess formation in a 29-year-old patient after her first delivery. Following an exploratory laparotomy, a uterine negative-pressure wound treatment (NPWT) was performed, successfully avoiding hysterectomy and enabling secondary suture of the uterine wall. This is the first report in the literature of such a treatment being used on a uterus.

*Corresponding author: Ioannis Dedes, MD, University Hospital of Zurich, Department of Gynecology and Obstetrics, Zurich, Switzerland, E-mail: ioannis.dedes@usz.ch

Franziska Krähenmann, Gian-Piero Ghisu, Esther Birindelli, Roland Zimmermann and Nicole Ochsenbein: University Hospital of Zurich, Department of Gynecology and Obstetrics, Zurich, Switzerland

\section{Case}

A 29-year-old primipara patient underwent a cesarean section at 39.4 weeks of gestation due to arrest of descent in the first stage of labor and chorioamnionitis $\left[38.9^{\circ} \mathrm{C}\right.$ fever, elevated leucocytes (Lc) $14.1 \mathrm{G} / \mathrm{L}, \mathrm{C}$-reactive protein (CRP) $32 \mathrm{mg} / \mathrm{L}$ ] after induction of labor in the context of intrahepatic cholestasis of pregnancy. A cesarean section was performed through a Pfannenstiel skin incision and a low transverse uterine incision, which had to be extended to a T-shaped incision due to difficult delivery of the impacted fetal head. Ceftriaxone $2 \mathrm{~g}$ i.v. was given during surgery.

A female neonate weighing $2800 \mathrm{~g}$, with a 5-min Apgar score of 8 and an umbilical artery pH of 7.30, was delivered. The uterine incision was closed using Polysorb ${ }^{\circledR}$ sutures (Covidien). Continuous closure of the peritoneum parietale and the fascia were performed with a running Polysorb ${ }^{\circledR}$ 2-0 suture. The subcutaneous tissue was adapted with interrupted Polysorb ${ }^{\circledR}$ 2-0 sutures, and staples were used to close the skin. The estimated blood loss was $600 \mathrm{~mL}$.

Approximately $48 \mathrm{~h}$ postpartum, the patient's body temperature rose to $41.7^{\circ} \mathrm{C}$ despite administration of paracetamol (4 g i.v./day), with elevated infection parameters (Lc $14.8 \mathrm{G} / \mathrm{L}$; CRP $194 \mathrm{mg} / \mathrm{L}$ ) despite continuous administration of ceftriaxone ( $2 \mathrm{~g}$ i.v.). Blood cultures revealed Escherichia coli extended spectrum beta lactamase (ESBL). Ceftriaxone was stopped and ertapenem (1 g i.v.) was administered on day 3 after surgery. Despite a good clinical condition, intermittent fever spikes and high infection parameters (Lc $16 \mathrm{G} / \mathrm{L}$, CRP $265 \mathrm{mg} / \mathrm{L}$ ) persisted. An abdominal ultrasound examination and computed tomography (CT) scan (Figure 1) on day 10 after surgery revealed a collection of fluid at the uterine incision, without other foci of infection. An exploratory relaparotomy confirmed an abscess at the uterotomy site, with evacuation of $200 \mathrm{~mL}$ pus. Meticulous debridement with irrigation of the uterine wall was performed, and two intra-abdominal drains were installed. Swabs taken intraoperatively confirmed E. coli ESBL, and the antibiotic regime with ertapenem was continued. 


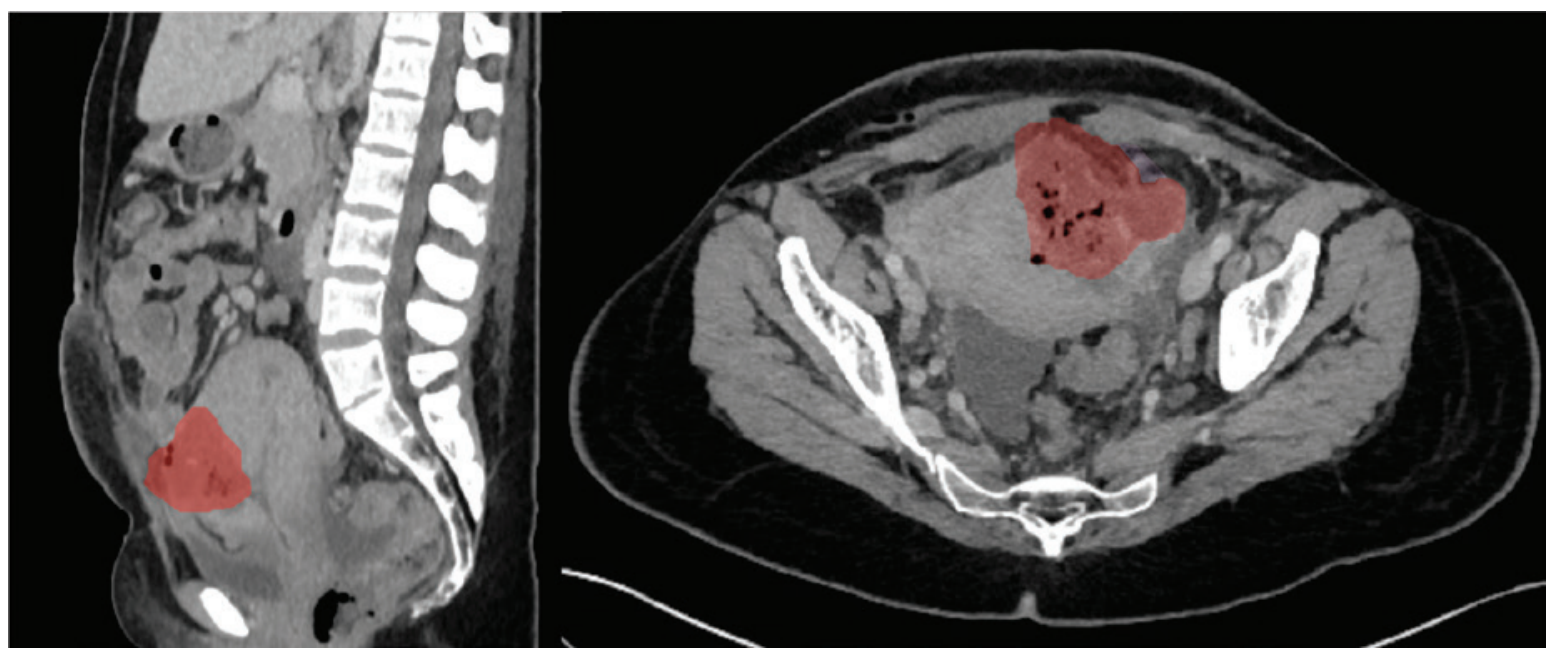

Figure 1: Contrast-enhanced CT obtained on post-cesarean day 10 demonstrates fluid collection with gas formation in the anterior myometrium (red), suggesting uterine incisional necrosis and abscess-formation: (Left) transvers sectional plane. (Right) sagittal sectional plane.

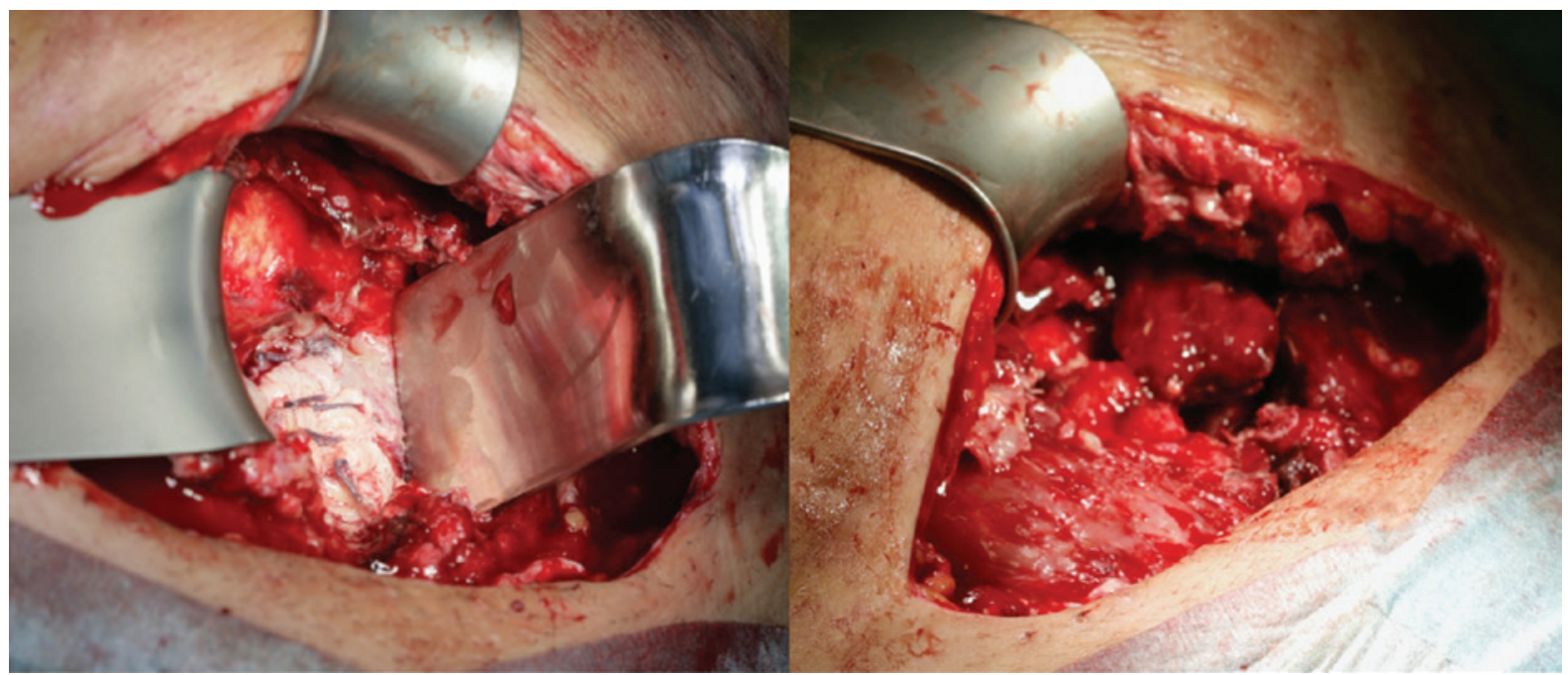

Figure 2: Intraoperative situs showing necrosis of the uterine wall: before (left) and after debridement (right).

Seven days after the re-laparotomy, a hypoechogenic collection was observed at the uterine wall by follow-up ultrasound and CT scan, highly suggestive of an abscess reformation. A third laparotomy was performed (Figure 2), which showed a partial dehiscence over $3 \mathrm{~cm}$ with necrosis at the uterine incision site. The fascia was unimpaired. An evacuation of the abscess was performed, with careful debridement of the necrotic parts and irrigation. An NPWT was installed at the site of the dehiscence in order to preserve the uterus. Kerlix ${ }^{\circledR}$ antimicrobial large roll gauze was applied to the uterine wound with open-cell foam dressings on top, surrounded by two-layer drainage foil (Suprasorb ${ }^{\circledR}$ CNP; Lohmann \& Rauscher) to protect the intestine and leading through the abdominal wall throughout the skin, sealing off the dressing. A continuous negative pressure of 40-50 mm Hg was applied. Microbiological samples taken intraoperatively revealed Ureaplasma, Candida albicans, and Bacteroides fragilis, and the antimicrobial regimen was extended to fluconazole $150 \mathrm{mg}$, azithromycin 1, and metronidazole $2 \mathrm{~g} /$ day. The dressings were changed every 2-3 days over a period of nearly 3 weeks, and a secondary closure of the uterotomy was performed with interrupted Vicry ${ }^{\circledR}$ (Ethicon) 0 sutures on day 35 after cesarean section.

On day 39, the patient redeveloped fever (up to $39.2^{\circ} \mathrm{C}$ ) due to a urinary tract infection with Pseudomonas aeruginosa, treated with ciprofloxacin $1.5 \mathrm{~g} /$ day. Using 


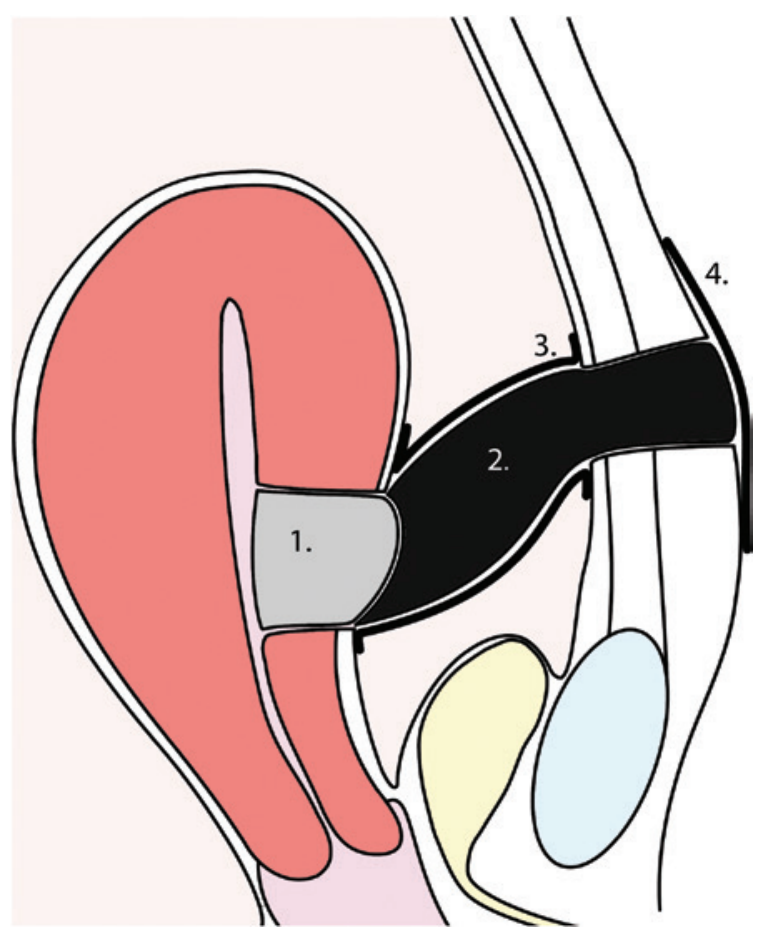

Visualization of the applied NPWT: (1) Kerlix ${ }^{\circledR}$ antimicrobial large roll gauze (2) open-cell foam dressing (3) two-layer drainage foil (Suprasorb ${ }^{\circledR}$ CNP; Lohmann \& Rauscher) (4) adhesive foil sealing off the dressing.

magnetic resonance imaging (MRI), any further surgical site infections or de novo uterine dehiscence were ruled out (Figure 3). The patient was discharged after 50 days. Six weeks later, an ultrasound revealed normal findings

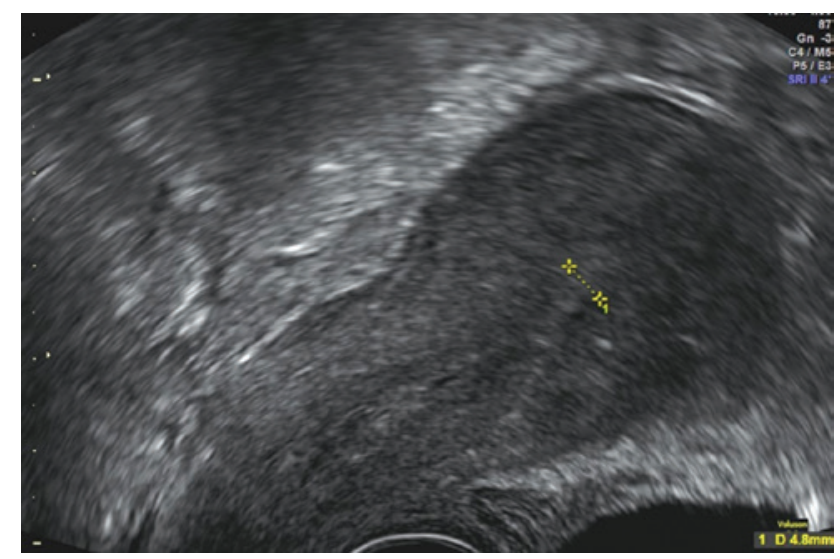

Figure 4: Transvaginal Ultrasound scan of the uterus in sagittal plane 4 weeks after discharge, showing unimpaired anterior uterine wall and endometrial layer of $4.8 \mathrm{~mm}$.

(Figure 4). An MR scan of the pelvis 18 months after cesarean section revealed a physiological scar on the uterus.

\section{Discussion}

This is the first report of NPWT applied to the uterus. NPWT is used in surgery to treat a variety of wounds, ranging from superficial ulcers or meshed grafts to deep infected and dehisced wounds, as well as open abdomen treatment [3]. The basic effects of NPWT on wounds is the evacuation of localized wound edema, reduced bacterial

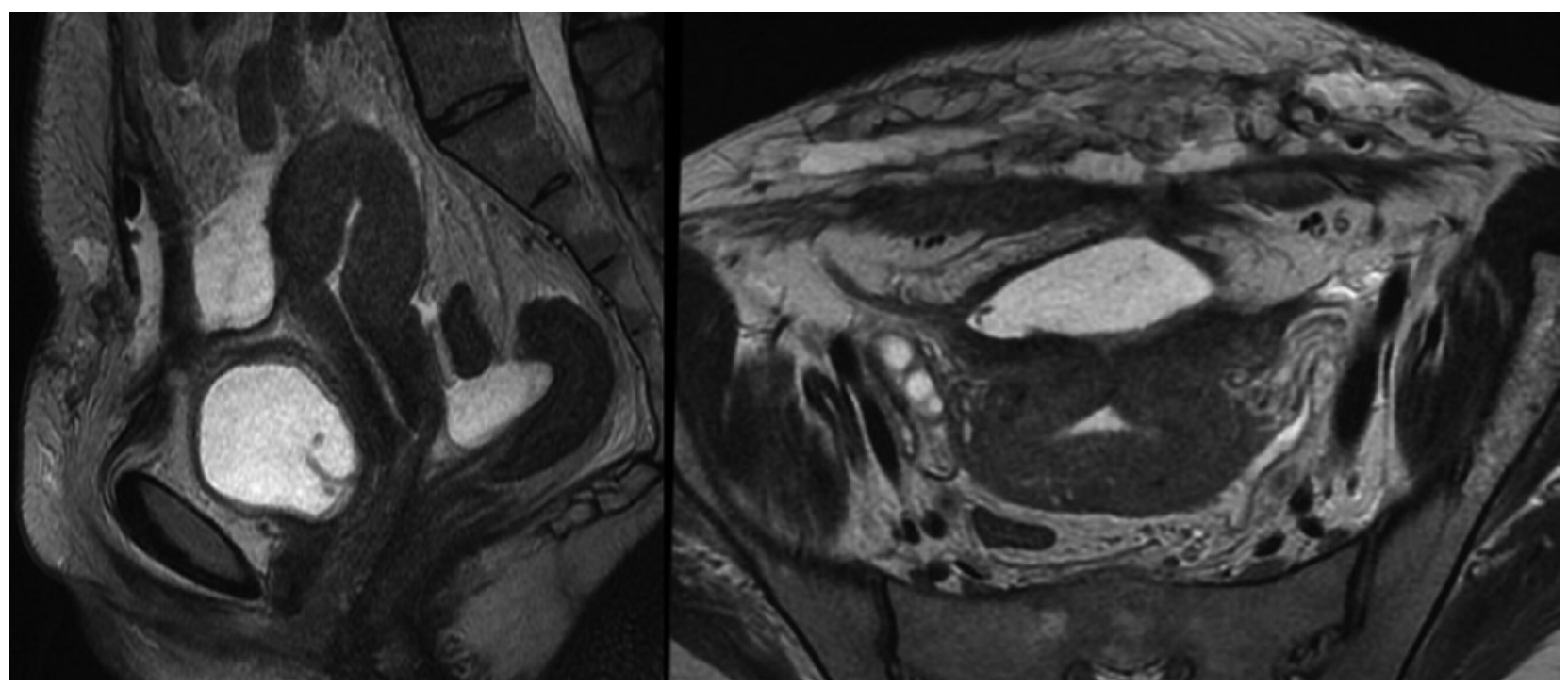

Figure 3: MRI of pelvis after secondary suture of the uterine incisional dehiscence shows postoperative fluid collection anterior to the uterotomy. (Left) sagittal sectional plane. (Right) transvers sectional plane. 
colonization, increased local blood flow, better oxygenation, and stimulation of granulation tissue growth [4].

In suspected metritis, improvement under antibiotic treatment usually follows within $72 \mathrm{~h}$ in nearly $90 \%$ of the cases [2]. Persistence of fever after this interval mandates a search for complications of metritis, such as phlegmon or abscess formation. These complications, over the long run, may lead to necrosis and separation due to extensive cellulitis of the uterine incision. The usual management of uterine incisional necrosis is hysterectomy $[2,5]$; uterus-preserving surgery has been reported in only a few cases. In one case, only peritoneal cleansing and antibiotic lavage were performed [6]. In two other cases, re-suture of the uterine incisional necrosis was reported [1, 7].

The addition of complementary therapy with NPWT to the traditional treatment with surgery and antimicrobial regimens might decrease the rate of hysterectomy in infectious post-cesarean uterine incision dehiscence. An MRI examination one and a half years later revealed a physiological scar on the uterus of the patient in this case report, but it is unclear whether a regular uterine cavity was achieved with this treatment.

\section{References}

[1] Rivlin ME, Hunt JA, Rubin A. Continual postoperative antibiotic peritoneal lavage in diffuse peritonitis complicating cesarean section. J Reprod Med. 1984;29:173-8.

[2] Cunningham FG GN, Lev- eno KJ, Gilstrap LC III, Hauth JC, Wenstrom KD, et al. Puerperal infections - clinical course. Williams Obstetrics. 23rd. New York, NY: The McGraw-Hill Group; 2010. p. 717.

[3] Bruhin A, Ferreira F, Chariker M, Smith J, Runkel N. Systematic review and evidence based recommendations for the use of negative pressure wound therapy in the open abdomen. Int J Surg. 2014;12:1105-14.

[4] Desai KK, Hahn E, Pulikkottil B, Lee E. Negative pressure wound therapy: an algorithm. Clin Plast Surg. 2012;39:311-24.

[5] Sengupta Dhar R, Misra R. Postpartum uterine wound dehiscence leading to secondary PPH: unusual sequelae. Case Rep Obstet Gynecol. 2012;2012:154685.

[6] Rivlin ME, Carroll CS, Morrison JC. Conservative surgery for uterine incisional necrosis complicating cesarean delivery. Obstet Gynecol. 2004;103(5 Pt 2):1105-8.

[7] Treszezamsky AD, Feldman D, Sarabanchong VO. Concurrent postpartum uterine and abdominal wall dehiscence and Streptococcus anginosus infection. Obstet Gynecol. 2011;118(2 Pt 2):449-51.

The authors stated that there are no conflicts of interest regarding the publication of this article. 